\title{
An Empirical Study about the Influence of the Nominal Effective Exchange Rate on Domestic CPI: Evidence from China
}

\author{
Wen Yun-dong \\ School of Economics and Management, WuHan University
}

ABSTRACT: This research aims to choose China as the research sample to conduct the empirical analysis about the influence of the nominal effective exchange rate on domestic CPI. It can be concluded from this research that the RMB nominal effective exchange rate will have negative influence on the domestic CPI.

KEYWORD: Domestic CPI; Inflation Rate; Empirical Research; Nominal Effective Exchange Rate

\section{INTRODUCTION}

China's government takes various measures to deal with the international financial crisis. With China's recovery from the international financial crisis, the inflation rate increase sharply. Hence different scholars put forward various measures to face up to the increasing inflation rate (Wang, Xiong and Liu, 2009). One of their opinions proposes that increasing the RMB exchange rate will be helpful to decrease the inflation rate in China. However, several scholars disagree with the opinion (Wang, Xiong and Liu, 2009). Hence this research aims to choose China as the research sample to conduct the empirical analysis about the influence of the nominal effective exchange rate on domestic CPI. This research consists of 5 parts. The first part aims to make brief introduction about this research. The second part will review the literature about the relationship between the exchange rate and CPI. The third part will analyze the econometric methodology of this research. The next part will conduct the empirical analysis and present the empirical results. The final part will make several conclusions in line with the analysis above.

\section{LITERATURE REVIEW}

In the beginning, this section will review the literatures about the factors to affect the CPI, which will be useful to establish the empirical model from the perspectives of the money supply, interest rate, GDP gap, external shocks. Then the empirical analysis about the influence of the nominal effective exchange rate on domestic CPI will be reviewed.
It argued that the domestic CPI will be considerably affected by the exchange rate (Auer and Chaney, 2009). The variation of the exchange rate will has significant effect on the prices of import products (Brzozowski, 2006). On one hand, the import consumption products will directly result in the change of CPI. On the other hand, the import intermediary products will significantly affect the domestic CPI through the intermediary variable of PPI (Production price index). Brzozowski's (2006) theoretical study about the CPI and exchange rate indicates that CPI and interest rate will affect each other. Lahrèche-Révil and Méjean (2008) attempt to make use of the VAR (Vector Auto-regression) model to investigate the interest rate on CPI; the result of impulse response analysis show that one unit variation of exchange rate will result in 0.23 unit of CPI.

Grossmann and Simpson (2010) make use of the correlation analysis to investigate the interrelationship among the exchange rate, interest rate and CPI; Grossmann and Simpson's (2010) correlation analysis shows that CPI is significantly correlated with the exchange rate. What's more, Grossmann and Simpson (2010) make use of the VAR model to analyze the influence of exchange rate on domestic CPI; the VAR analysis reveals the lagged influence of exchange rate. One unit variation of exchange rate will give rise to 0.37 unit variation of CPI. In addition, Coleman and Karagedikli (2012) choose the VAR model and impulse response function to investigate the relationship among of Brazil's exchange rate, domestic CPI and interest rate; the impulse response results reveal that about $28 \%$ of the initial impulse about the exchange rate will be responded by Brazil's CPI. 
Apart from the previous studies about exchange rate to affect the domestic CPI, there are several important factors have influence on domestic CPI. Firstly, The money supply and need is one of the important factors to affect the CPI. (Bhattacharya and Thomakos, 2008; Grossmann and Orlov ,2012) Secondly,it is proposed that the interest rate will significantly affect the CPI through the following channels (Cai, Chou and Li, 2009;Cavoli,2008). In the beginning, the interest rate will affect the capital costs for the corporations, which will finally give rise to the effect on the corporate production costs. Then the interest rate will give rise to the change of investment sentiment. It will have significant impact on the domestic investment needs. Finally, the interest rate will have an effect upon the domestic economic growth of one country, which will give rise to the changing demand and supply in the product market. Hence it will affect the product prices.Thirdly,GDP gap indicates the aggregate need factors in the product market, which will directly affect the product market equilibrium. Hence it will affect the product price and domestic CPI. Finally, external shock is an assignable factor to affect the CPI.On one hand, the external shock will give rise to the change of corporate manufacturing costs, which will affect the prices of consumption products. On the other hand, the external shock will directly affect the CPI when the external shocks belong to the final consumption goods(Fratzscher, Juvenal and Sarno,2010),Sarno,2010; Chaban,2011)..

\section{MODEL AND VARIABLES}

According to the conceptual analysis framework, this report aims to come up with the following linear regression model. In the empirical model, the independent variables include the external shock $(\varepsilon)$, nominal effective exchange rate(NEER), interest rate $(I R)$, GDP gap $(G A P)$ and money supply $(M 1)$. The dependent variable refers to the domestic $\mathrm{CPI}$ in China.

$$
\begin{aligned}
& C P I=\beta_{0}+\beta_{1} * O I L+\beta_{2} * N E E R+\beta_{3} * I R+ \\
& \beta_{4} * G A P+\beta_{5} * M_{1}+\varepsilon
\end{aligned}
$$

As this report aims to choose China as the research sample to conduct the empirical analysis about the relationship between the nominal effective exchange rate and CPI, the symbols in the equation can be seen as follows. (1) CPI refers to the consumer price index (CPI) in China. (2) $\beta_{0}$ refers the estimated constant. (3) $\beta_{1}, \beta_{2}, \beta_{3}, \beta_{4}, \beta_{5}$ separately stand for the estimated coefficients of the external shock, nominal effective exchange rate, interest rate, GDP gap and money supply. The symbols own the similar meanings in the following paragraphs.

\section{THE EMPIRICAL ANALYSIS}

Then we will make a empirical study on the model. Firstly, this section will make use of Eviews 5.0 software to conduct the descriptive statistic analysis about the collected data; it indicates that the maximum and minimum of the CPI are respectively 114.99 and 91.97; while the maximum and minimum of NEER are separately 120.62 and 93.63 . The means of CPI and NEER are 99.4 and 104.99. Besides, the standard deviation can reflect the fluctuation range of the collected time-series data.

Secondly, this report makes use of the ADF unit test to evaluate stability of the variables. Testing the stability of the time-series data will be beneficial to eliminate the spurious regression. Firstly, we will transform all the variables into the form of natural logarithm, then, this report will change the symbols to represent the variables after conducting the natural logarithm. For example, the variable NEER will be named as LNNEER after conducting the natural logarithm. The relevant results can be seen as follows.

$\triangle$ LNCPI indicates the first order difference of the LNCPI; the other symbols will own the similar meanings. it indicates that all the variables (nominal effective exchange rate, CPI, oil price, adjusted industrial added value, money supply (M1) and the average weighted inter-bank offered rate) are instable at the critical level of 0.05 . However, the first order differences about these variables belong to the stable time-series data at the critical level of 0.05. Thirdly, this research chooses E-G two steps method to assess the co-integration relationship among the variables. As all the variables have one unit root, this section will make use of the E-G two steps method to empirically analyze the impact of exchange rate on China's CPI. The first step in the E-G two steps method can be revealed as follows.

Table 1. The first step in the E-G two steps method

\begin{tabular}{|c|c|c|c|c|}
\hline variables & Coefficients & $\begin{array}{c}\text { Standard } \\
\text { variance }\end{array}$ & T-test & P-value \\
\hline Constant & 3.053 & 0.132 & 23.13 & 0.00 \\
\hline LNGAP & 0.333 & 0.031 & 10.74 & 0.00 \\
\hline LNOIL & 0.036 & 0.005 & 7.52 & 0.00 \\
\hline LNM1 & 0.206 & 0.028 & 7.27 & 0.00 \\
\hline LNNEER & -0.208 & 0.022 & -9.46 & 0.00 \\
\hline LNIR & -0.053 & 0.004 & -14.64 & 0.00 \\
\hline
\end{tabular}

Based on the residual series in the first stage, this research will make use of the ADF test to assess the stability of the residual series. The results of the second step can be seen in the table 2 . 
Table. 2 Results of the second step in E-G two steps method

\begin{tabular}{|c|c|c|c|}
\hline Significance & Critical value & T-test & P-value \\
\hline $1 \%$ & -2.58 & -4.06 & 0.00 \\
\hline $5 \%$ & -1.94 & -4.06 & 0.00 \\
\hline $10 \%$ & -1.62 & -4.06 & 0.00 \\
\hline
\end{tabular}

The results in the table 2 show that the residual series is stable at the critical level of 0.01 . In other words, the results indicate that the co-integration relationship exists among nominal effective exchange rate, CPI, oil price, adjusted industrial added value, money supply and the interest rate. What's more, the estimated coefficient of LNNEER is -0.208 . It indicates that one unit appreciation of RMB will give rise to 0.208 decreasing unit of CPI. The negative coefficient of LNNEER indicates that the RMB exchange rate is negatively correlated with the CPI.

Finally, this research will choose depend on the Eviews 5.0 software and the error correction model to analyze the short-term relationship among the variables. The estimated coefficients of the relevant variables can be seen in the table 5. The symbol (DLNNEER) stands for the first order difference of the LNNEER. The other symbols will own the similar meanings. The P-values of the estimated coefficients are below 0.05 . It shows that that the estimated coefficients are significant at the critical level of 0.05. In addition, the F-statistic (6.03) and the relevant P-value (0.00) show that the model is also significant at the critical level of 0.05 . Hence the empirical results can be reflected in the following equation.

$$
\begin{aligned}
& \triangle L N C P I=-0.007+0.769 \Delta L N G A P-0.09 \Delta L N N E E R- \\
& 0.02 \Delta L N I R+0.045 \Delta L N O I L+0.054 \Delta L N M_{1}-0.05 E C M(-1)
\end{aligned}
$$

The coefficient of ECM(-1) reflects the shortterm influence. The estimated coefficient $(-0.05)$ of $\operatorname{ECM}(-1)$ indicates that the modification speed is 0.05 in the condition that the short-term variation deviates from the long-term equilibrium. In addition, the influence coefficient of RMB exchange rate on China's CPI is -0.09 , which can be inferred from the estimated coefficient (-0.09) of DLNNEER. In other words, the RMB appreciates $1 \%$, China's CPI will decrease $0.09 \%$.

\section{CONCLUSIONS}

As the relationship between the nominal effective exchange rate and CPI in China attracts close attention of scholars and governments, this research aims to conduct the empirical analysis about this issue. Based on the analysis, it can be concluded that the RMB nominal effective exchange rate will have negative influence on the domestic CPI. The empirical results are similar with the Corden's (2009) empirical analysis, which also supports the negative impact of RMB nominal effective exchange rate on the CPI.

The limitations of this research can be outlined in the following aspects.

(1) In line with the literature review about the factors to affect the domestic CPI, it can be inferred that the chosen indicators may affect the empirical results. Hence it is helpful for the future researchers to choose the more appropriate indicators to conduct the empirical study.

(2) This research ignores the influence of the international financial crisis on the estimated coefficients in the empirical model. It may give rise to inaccurate empirical results. Hence the dummy variables can be chosen in the empirical model to reflect the impact of the international financial crisis on the estimated coefficients.

\section{REFERENCES}

[1] P. Auer, T. Chaney. Exchange Rate Pass-Through in a Competitive Model of Pricing-to-Market. Journal of Money, Credit and Banking, 2009, 41(1):151-175.

[2] P.S. Bhattacharya, D.D. Thomakos. Forecasting industrylevel CPI and PPI inflation: Does exchange rate passthrough matter? International Journal of Forecasting, 2008, 24(1): 134-150.

[3] BIS. Available at: http://www.bis.org (accessed at: 24th March, 2012).

[4] M. Brzozowski. Does One Size Fit All? The CPI and Canadian Seniors. Canadian Public Policy, 2006, 32(4): 387-411.

[5] China's National Bureau of Statistics. Available at: http://www.stats.gov.cn/english/ (accessed at: 24th March, 2012).

[6] Y.J. Cai, R.Y. Chou, D. Li. Explaining international stock correlations with CPI fluctuations and market volatility. Journal of Banking \& Finance, 2009, 33(11): 2026-2035.

[7] T. Cavoli. The exchange rate and optimal monetary policy rules in open and developing economies: Some simple analytics. Economic Modelling, 2008, 25(5): 1011-1021

[8] M. Chaban. Home bias, distribution services and determinants of real exchange rates. Journal of Macroeconomics, 2011, 33(4): 793-806.

[9] A. Coleman, O. Karagedikli. The relative size of exchange rate and interest rate responses to news: An empirical investigation. The North American Journal of Economics and Finance, 2012, 23(1): 1-19.

[10] W.M. Corden. China's Exchange Rate Policy, Its Current Account Surplus and the Global Imbalances. The Economic Journal, 2009, 119(541): 430-441.

[11] M. Fratzscher, L. Juvenal, L. Sarno. Asset prices, exchange rates and the current account. European Economic Review, 2010, 54(5): 643-658.

[12] A. Grossmann. and A.G. Orlov. Exchange Rate Misalignments in Frequency Domain. International Review of Economics \& Finance, 2012: 15-37.

[13] A. Grossmann, M.W. Simpson. Forecasting the Yen/U.S. Dollar exchange rate: Empirical evidence from a capital 
enhanced relative PPP-based model. Journal of Asian Economics, 2010, 21(5): 476-484.

[14] C.Y. Horioka, J. Wan. The Determinants of Household Saving in China: A Dynamic Panel Analysis of Provincial Data. Journal of Money, Credit and Banking, 2007, 39(8):2077-2096.

[15] A.Lahrèche-Révil, I. Méjean. Exchange-Rate PassThrough at the Product Level Guillaume Gaulier, The Canadian Journal of Economics, 2008, 41(2): 425-449.
[16] O. C. Ricardo, E.D. Nosal. Some Benefits of Cyclical Monetary Policy. Economic Theory, 2009, 39(2): 195216.

[17] L. Wu, Y. Heng. Corporate Tax, Capital structure and the accessibility of bank loans: evidence from China. Chinese Academy of Management Annual Meeting, 2006: 12-23.

[18] T. Ito, K. Sato. Exchange Rate Changes and Inflation in Post-Crisis Asian Economies: Vector Autoregression Analysis of the Exchange Rate Pass-Through. Journal of Money, Credit and Banking, 2008, 40(7), pp. 1407-1438. 